Pirineos, 149-150: 121 a 144, JACA; 1997

\title{
LA PRECIPITACIÓN MEDIA ANUAL EN EL SECTOR ALTO DE LA CUENCA DEL CINCA (PIRINEO ARAGONÉS, ESPAÑA)
}

\author{
JAVIER DEL VALLE MELENDO \\ Dr. en Geografía. Consultor técnico de la Oficina de Planificación Hidrológica de la Confederación \\ Hidrográfica del Ebro. Paseo de Sagasta, 24. 50.006 Zaragoza (España).
}

\begin{abstract}
RESUMEN.- El sector alto de la cuenca del Cinca, situado en la vertiente meridional del Pirineo central, es una zona de relieve accidentado y precipitación media abundante, en la que se observa un importante gradiente altitudinal. Para la caracterización pluviométrica es importantísimo disponer de datos obtenidos a diferentes alturas, por lo que hemos utilizado los recogidos por los pluviómetros del Instituto Nacional de Meteorología en algunos pueblos de la zona, y los de los totalizadores instalados por las compañías eléctricas, normalmente a considerable altitud. Las correlaciones precipitación-altura realizadas en los tres sectores en los que hemos dividido el alto Cinca revelan comportamientos muy diferentes entre ellos, con gradientes progresivamente menores en sentido $O-E$, lo cual queda reflejado en el mapa de isoyetas.
\end{abstract}

SUMMARY.- Upper Cinca basin, located on the southern side of the Pyrenees, is a rugged topography area with abundant average precipitation where an important altitudinal gradient is observed. It is very important, for the pluviometric description, to make use of data originated from different heights. We have used the data from the Meteorologic National Institute (INM) raingages, located in some villages of the area, and from the totalizators set up by the electric power companies at great heights. The rainfall-height correlations done for the three areas in which we have divided Upper Cinca basin show different perfomance, with gradients becoming less and less intensive from $W$ to $E$, which is shown in the annual mean rainfall map.

RÉSUMÉ.- La haute vallée du Cinca, située dans le versant méridional des Pyrenées centrales, est une zone de relief accidenté avec des précipitations abondantes où l'on observe un gradient d'altitude importante. Pour la caractérization pluviométrique il est très important disposer des données qui soient obtenues à des altitudes différentes. Pour célà.nous avons utilisé les collectes des pluviomètres de 


\begin{abstract}
l'Institut national de métérologie prises en quelques villages de la région, et celles provénant des totalizateurs déjà instalés para les compagnies d'éléctricité, lesquelles se trouvent à une altitude élévée. Les corrélations précipitation-altitude réalisés dans le Haut-Cinca mettent en évidence des comportements très differents entre les trois secteurs étudiés, avec des gradients progréssivemente moins accentués d'O en E., ce qui est montré dans la correspondante carte des isohyètes.
\end{abstract}

\title{
1. Introducción
}

Es de sobras conocido que la precipitación media aumenta en las zonas de montaña respecto al entorno próximo. Este hecho claro, en ocasiones es difícilmente cuantificable debido a la escasez de pluviómetros con series largas y continuas instalados en altura, pues en la mayoría de los casos éstos se encuentran instalados en los pueblos, y por lo tanto en los valles o medias laderas. Este hecho obliga a deducir la precipitación que reciben las zonas elevadas estableciendo correlaciones entre la precipitación y la altitud de estos pluviómetros localizados en cotas bajas, lo que es fiable (siempre que el coeficiente de correlación sea elevado) hasta una cierta altitud, a partir de la cual no se puede asegurar que la recta de regresión obtenida refleje el comportamiento de la precipitación. El margen de incertidumbre es, por lo tanto, muy amplio, por lo que es de gran ayuda disponer de series de datos obtenidos en alta montaña, para así poder establecer correlaciones más generales y disminuir en lo posible el margen de error.

Otro problema que nos encontramos al caracterizar pluviométricamente las zonas de montaña es el de las marcadas diferencias que en ocasiones se producen entre áreas próximas, debido a su diferente orientación respecto a los vientos húmedos, la presencia de barreras topográficas, etc. Como consecuencia, en ocasiones es difícil obtener un buen ajuste precipitación-altitud, o se observan lugares notablemente separados de la recta de regresión, cuyas características pluviométricas particulares responden, en buena medida, a razones de localización o topografía local.

\section{2. Área de estudio}

El sector alto de la cuenca del Cinca se localiza en la vertiente meridional del Pirineo Central. Limita al N con Francia (cuenca atlántica del Garona), de la que está separada por importantes macizos y cordales montañosos. $\mathrm{Al} \mathrm{O}$ está limitada por la cuenca del Gállego (concretamente por las cuencas de sus 
afluentes Caldarés y Sía). Su límite oriental lo señalan las cuencas del Noguera Ribagorzana y del Garona en su extremo nororiental, al cual fluye por vía subterránea una parte de lo que superficialmente corresponde con la cabecera del Ésera, sector que hemos incluido en el presente estudio.

El límite meridional no es tan claro como los límites geográficos y en algunos casos administrativos que hemos descrito hasta el momento, por lo que lo hemos tenido que definir previamente. Hemos considerado la desembocadura del río Chate, afluente del Ara y de los congostos de Las Devotas en el Cinca y el Ventamillo en el Ésera. En estos dos últimos casos los mencionados estrechos indican barreras orográficas claras que separan zonas de características paisajísticas diferentes. En el caso del Ara no hay ningún obstáculo tan marcado hasta la cerrada de Jánovas, mucho más al sur, y la transición paisajística a lo largo de su recorrido es mucho más progresiva, por lo que el límite señalado es algo más arbitrario.

La zona considerada se caracteriza por una topografía de fuertes relieves. En ella se localizan algunos de los macizos montañosos más importantes de la cordillera, tales como los de las Tres Sorores, entre las cabeceras del Cinca y del Arazas, Posets, entre las del Cinqueta y el Ésera, Aneto-Maladeta, al E de la del Ésera, o Vignemale, al E de la cabecera del Ara. Entre ellos se abren profundos valles en algunos casos bastante cerrados por estos y otros macizos montañosos y sierras. Así, el resultado es un territorio muy compartimentado y con una fuerte energía de relieve, con importantes altitudes que superan en numerosos puntos los $3000 \mathrm{~m}$ e incluso los $3300 \mathrm{~m}$ en los macizos mencionados, entre los que se desarrollan valles que en buena parte localizan su fondo entre 1000 y $1500 \mathrm{~m}$. Esta abrupta y compartimentada orografía es responsable en buena medida de diferencias climáticas muy destacables según la altitud, la orientación, la exposición a los vientos húmedos dominantes, etc. Para su análisis detallado sería necesario disponer de una red de observatorios, al menos termopluviométricos, mucho más densa que la actual y capaz de abarcar la media y alta montaña de la cordillera, además de los valles.

La localización de la zona de estudio en la vertiente meridional del sector central de la cordillera pirenaica permite que lleguen a ella las masas de aire responsables de la mayoría de la precipitación en la misma: las procedentes del Atlántico y las procedentes del Mediterráneo, aunque éstas tienen una menor capacidad de generar precipitación y su influencia se limita a las zonas mejor expuestas de los valles orientales, perdiendo importancia rápidamente hacia el O (CUADRAT, 1981). 


\section{Datos y metodología}

Cuando nos planteamos el presente trabajo, partimos de los estudios ya realizados (BORDERÍAS, 1975; PLANA, 1975; PUIGDEFÁBREGAS \& CREUS, 1976; CUADRAT, 1981; CREUS, 1983, 1987 Y GARCÍA RUIZ et al., 1985), y nos propusimos calcular la precipitación media anual del sector alto de la cuenca del Cinca dividiéndolo en las cuatro subcuencas que lo componen (Ara, Cinca, Cinqueta y Ésera), hallando para cada una de ellas por separado la correlación entre la precipitación media anual y la altitud mediante el método que ofreciera mejor ajuste, para así obtener información detallada sobre las características pluviométricas de cada una de ellas.

La metodología de hallar gradientes de precipitación-altitud por cuencas hidrográficas ya fue utilizada por GARCÍA RUIZ et al. (1985) en su estudio sobre los recursos superficiales del Alto Aragón. También posteriormente MARÍN (1988) en su "Estudio hidrológico de la cuenca alta y media del Gállego" empleó la delimitación natural de la cuenca hidrográfica de este río, y por lo tanto de dicha correlación. Así mismo del VALLE (1996) para analizar la precipitación del Prepirineo central y occidental aragonés y sus somontanos aplicó este método a la zona de estudio.

A nuestro juicio permite conseguir un mayor grado de detalle en la caracterización pluviométrica de la zona estudiada que la aplicación de una correlación regional única, pues posibilita tener en cuenta las divisorias de aguas que pueden influir en las condiciones pluviométricas según la procedencia de los vientos húmedos dominantes, especialmente si estas divisorias presentan relieves destacados, como suele ocurrir en las áreas de montaña. Por ello, nos parece adecuada su utilización en el presente trabajo, máxime cuando éste pretende, partiendo de los estudios previos, aportar un mayor grado de detalle al conocimiento de las características pluviométricas de esta zona.

Para conseguir unas correlaciones lo más reales posibles, consideramos importante incluir en ellas los datos de los pluviómetros totalizadores colocados por las compañías de electricidad, pues los observatorios del Instituto Nacional de Meteorología (I.N.M.) se localizan en su mayor parte en los pueblos situados en los valles, por lo que no ofrecen datos del territorio situado a mayor altitud. Estos pluviómetros totalizadores no ofrecen un cubrimiento completo y regular del espacio de media y alta montaña, pero aportan las únicas series de precipitación con alguna continuidad por encima de los $1500 \mathrm{~m}$, por lo que son muy útiles para complementar con sus datos a los observatorios pluviométricos localizados en los valles.

Por lo tanto, hemos utilizado dos fuentes de datos: 
a) Datos de los pluviómetros del Instituto Nacional de Meteorología

Hemos seleccionado a más de $1000 \mathrm{~m}$ en el sector alto de la cuenca, y hemos considerado el periodo 1961-1990 siempre que ha sido posible, y si no ha podido ser, hemos utilizado quince años, correspondientes con la primera o la segunda quincena de la treintena señalada.

Los observatorios y los periodos de datos que hemos utilizado son los siguientes:

- Valle del Ara

—Torla (mapa 1: n. ${ }^{\circ}$ 5). 1053 m. Serie 61 - 90.

-Broto (mapa 1: n. ${ }^{\circ}$ 6). 1005 m. Serie 61 - 90.

-Fragen (mapa 1: n. $\left.{ }^{\circ} 7\right) .1113 \mathrm{~m}$. Serie $76-90$.

—Asín de Broto (mapa 1: no 8). 1103 m. Serie 61 - 90 (1961 y 1962 fueron rellenados mediante correlación).

- Refugio de Góriz: fue desechado por disponer de una serie demasiado corta.

- Valle del Cinca

- Pineta «Presa»(mapa 1: $\left.\mathrm{n}^{\circ} 14\right) .1150 \mathrm{~m}$. Serie 61-90.

-Buerba (mapa 1: $\left.\mathrm{n}^{\circ} 15\right) .1143 \mathrm{~m}$. Serie 61-90.

- Barrosa «Central»(mapa 1: $\mathrm{n}^{\circ}$ 16). $1200 \mathrm{~m}$. Serie 61-90.

-Parzán (mapa 1: n 17). 1050 m. Serie 61-90 (1961 y 1962 fueron rellenados mediante correlación).

-Fanlo del Valle de Vió (mapa 1: $n^{\circ}$ 18). 1320 m. Serie 61-75.

- Valle del Cinqueta

-Plandescún «Presa» (mapa 1: no 24). $1100 \mathrm{~m}$. Serie 61-90

- Sin (mapa 1: $\mathrm{n}^{\circ}$ 25).1248 m. Serie 61-90 (1961 fue rellenado mediante correlación).

-Gistain (mapa 1: $\mathrm{n}^{\mathrm{o}}$ 23). $1422 \mathrm{~m}$. Serie 61-90 (1961 fue rellenado mediante correlación).

—San Juan de Plan (mapa 1: n²2). 1124 m. Serie 61-90 (1961 y 1962 fueron rellenados mediante correlación).

- Valle del Ésera

-Benasque «Vivero» (mapa 1: $\mathrm{n}^{\circ}$ 27). $1136 \mathrm{~m}$. Serie 61-75.

—Eriste «Central» (mapa 1: $\mathrm{n}^{\circ}$ 28). $1100 \mathrm{~m}$. Serie 61-90 (desde enero de 1961 hasta abril de 1964 fue rellenado mediante correlación).

Sus datos de precipitación media anual aparecen en la Tabla 1 y su localización en el Mapa 1. 


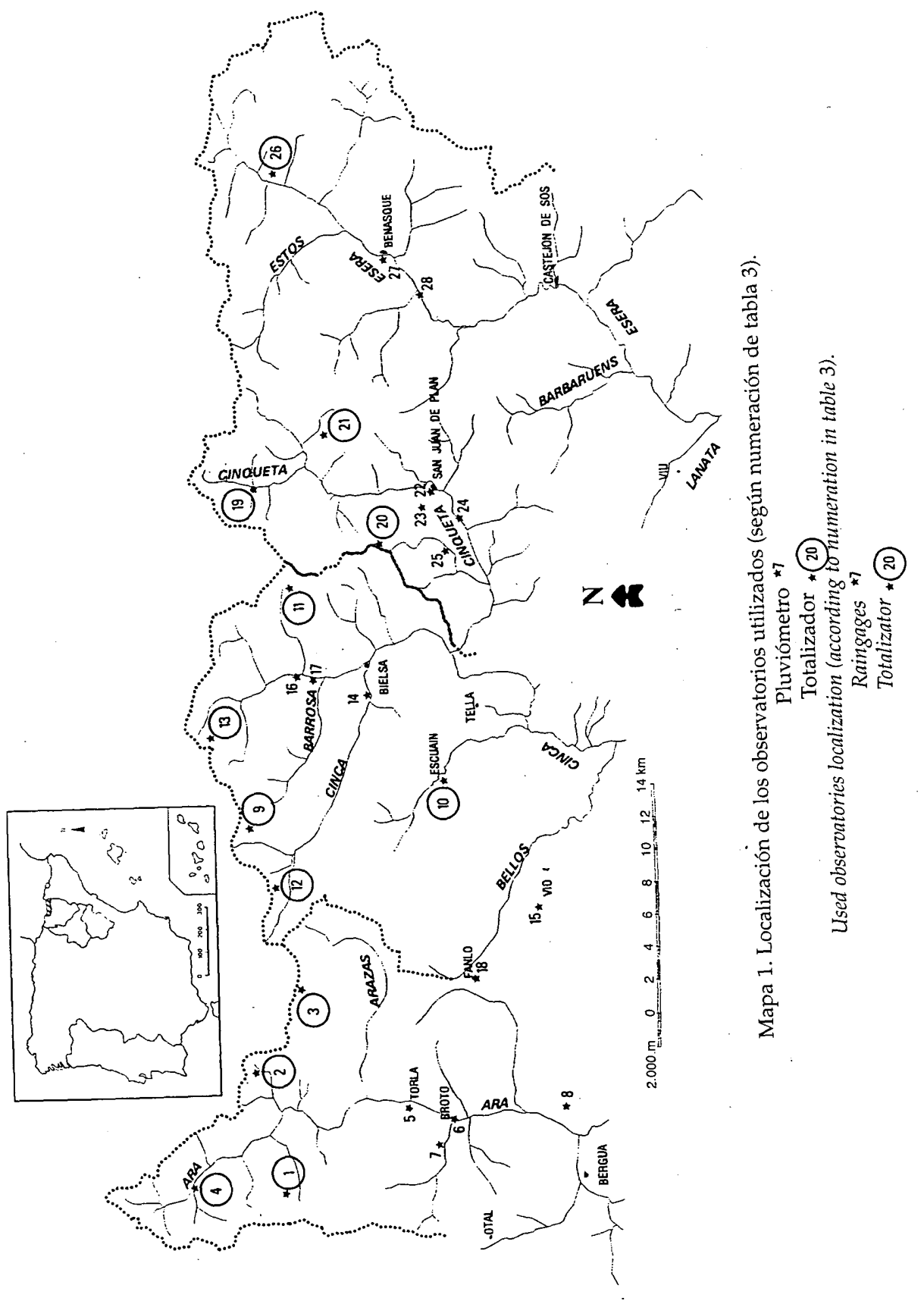

126 


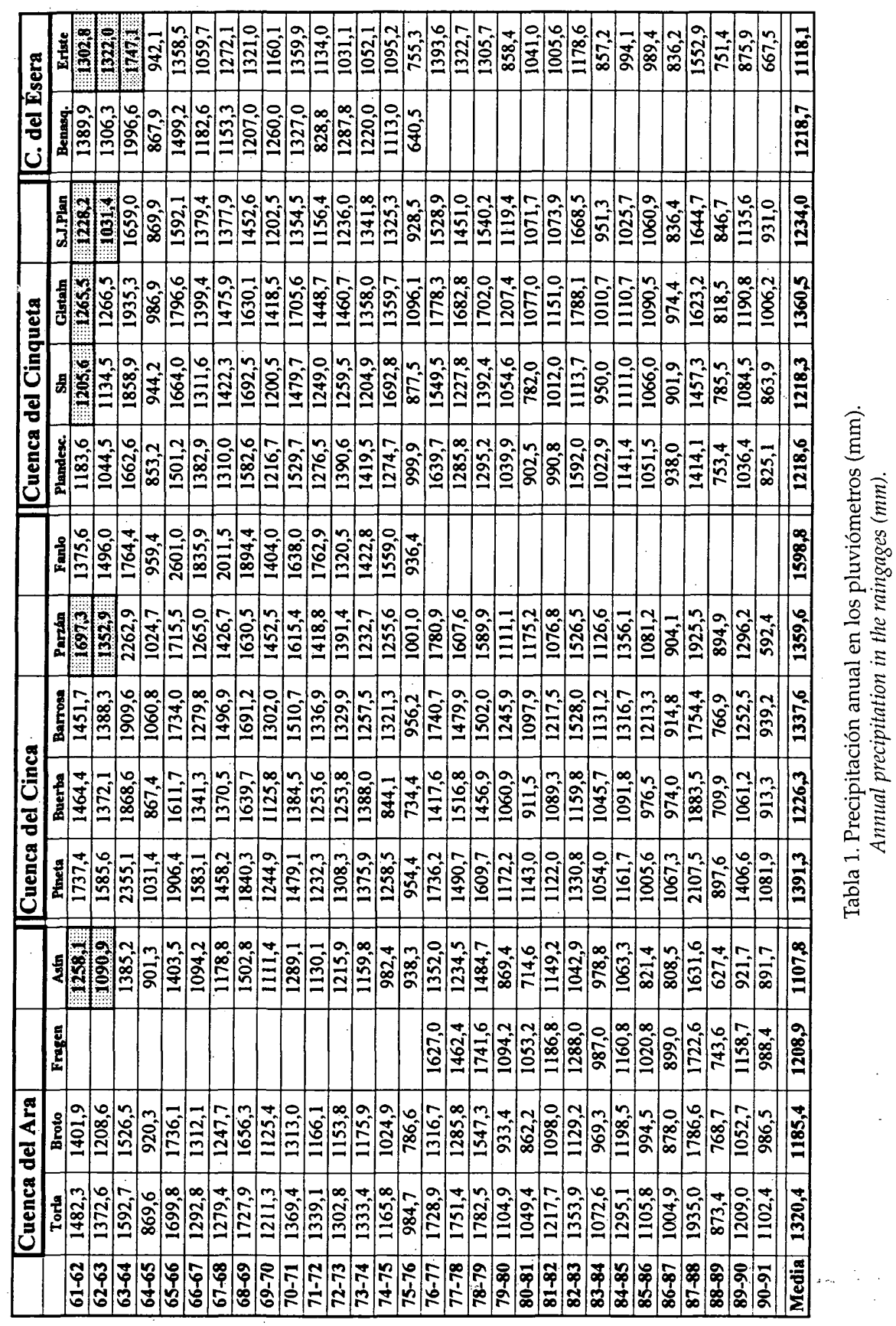


b) Datos tomados por los totalizadores colocados en altura por las compañias de electricidad

La toma de estos datos la realizan una vez al año (normalmente el 1 de julio) las compañías de electricidad, y su fiabilidad es algo menor que la de los pluviómetros de lectura diaria del I. N. M., porque aunque se intente minimizar, siempre hay algo de evaporación, o los pluviómetros sufren pérdidas por otras causas. No obstante, algunos de ellos ofrecen series relativamente largas, y son interesantísimos para la caracterización pluviométrica de estas montañas.

Los pluviómetros que hemos utilizado fueron instalados por Iberduero (posteriormente denominada Iberdrola), datos que fueron enviados posteriormente a Eléctricas Reunidad de Zaragoza (E. R. Z.) al comprar esta compañía los derechos de explotación del Cinca. Hemos de señalar, no obstante, que el situado en el Ésera (Baños de Benasque) fue instalado por Energía e Industrias Aragonesas (E. I. A.) S. A., posteriormente E. A. S. A., compañía absorbida por E. R. Z., por lo que todos los datos nos han sido facilitados por Eléctricas Reunidas de Zaragoza. Son los siguientes:

- Valle del Ara

-Otal (mapa 1: n. ${ }^{\circ}$ 1). 1862 m. Serie: Julio 61-Junio 91

- La Pazosa (mapa 1: n. ${ }^{\circ}$ 2). 2230 m. Serie: Julio 61-Junio 91 (rellenado por correlaciones Julio 61-Junio 65)

-Brecha de Rolando (mapa 1: n. ${ }^{\circ}$ 3). 2310 m. Serie:Julio 61-Junio 91 (rellenado por correlaciones Julio 61-Junio 64 y Julio 82-Junio 86).

—Los Batanes (mapa 1: n. ${ }^{\circ}$ 4). 2000 m. Serie Julio 61-Junio 91 (rellenado por correlaciones Julio 61-Junio 63)

- Valle del Cinca

- La Larri (mapa 1: n. ${ }^{\circ}$ 9). 2500 m. Serie Julio 63-Junio 82.

—Escuain (mapa 1: n. ${ }^{\circ}$ 10). 1340 m. Serie Julio 73-Junio 91

-Urdiceto (mapa 1: n. ${ }^{\circ} 11$ ). $2360 \mathrm{~m}$. Serie Julio 61-Junio 91

—Lago Marboré (mapa 1: n. ${ }^{\circ}$ 12). 2590 m. Serie Julio 61-Junio 91 (rellenado por correlaciones Jul 61-Jun 62 y Jul 64-Jun 65)

-Puerto Viejo (mapa 1: n. ${ }^{\circ}$ 13). $2030 \mathrm{~m}$. Serie Julio 61-Junio 91 (rellenado por correlaciones Julio 61-Junio 63 y Julio 66-Junio 67)

- Valle del Cinqueta

-Puerto La Pez (mapa 1: n. ${ }^{19}$ ). 1800 m. Serie Julio 61-Junio 91 (rellenado por correlaciones Jul 61-Jun 62)

—Cruz de Guardia (mapa 1: n. ${ }^{\circ}$ 20). 2120 m. Serie Julio 61-Junio 91 (rellenado por correlaciones Julio 61-Junio 65 y Julio 67-Junio 68)

—Millares (mapa 1: n. 21 ). 2390m. Serie Julio 61-Junio 91.

- Valle del Ésera

- Baños de Benasque (mapa 1: n. ${ }^{\circ}$ 26). 1720 m. Serie: Julio 62-Julio 63 y Julio 76-Junio 91 (rellenado por correlaciones Julio 76-Junio 77 y Julio 89-Junio 90) 
Sus datos de precipitación anual aparecen en la Tabla 2.

En primer lugar hemos realizado una homogeneización lo mayor posible de las series de los pluviómetros del I. N. M. y los totalizadores de las compañías eléctricas, aunque aquí nos hemos encontrado con alguna dificultad:

Los totalizadores no miden la cantidad de precipitación total del año civil, sino que sus mediciones se realizan normalmente el 1 de julio, por lo que no coinciden con las series anuales de los pluviómetros. Por ello, en los pluviómetros del I. N. M. hemos utilizado las medias de precipitación desde julio hasta junio, para así hacerlas coincidentes con los datos de los totalizadores, por lo que las series abarcan desde julio de 1961 hasta junio de 1991. En los casos en los que no ha sido posible disponer de toda la treintena y sólo se han utilizado quince años, las series terminan o comienzan en junio de 1976 (Tabla 1).

En las series con las que hemos trabajado hemos encontrado algunas faltas de datos debido a diversas causas, que han sido rellenadas mediante correlaciones:

- En los datos de los pluviómetros del I. N. M. los huecos de algunos meses han sido rellenados mediante correlaciones lineales con observatorios próximos, en los que se han obtenido coeficientes de correlación muy altos. Así se han completado las series elegidas y se han hallado las precipitaciones medias anuales.

- En los pluviómetros totalizadores algunos años no se han realizado lecturas, en la mayoría de los casos por encontrarlos rotos o deteriorados. Hemos realizado correlaciones lineales con totalizadores próximos, obteniendo también buenos resultados, lo que nos ha permitido completar sus series de observación.

Los datos obtenidos mediante correlación aparecen en las tablas 1 y 2 en negrita y con un sombreado.

Una vez homogeneizadas las series, hemos realizado las correlaciones entre la altitud y la precipitación media anual. Para ello, hemos dividido la zona en sectores, correspondientes con las cuencas fluviales del Ara, Cinca, Cinqueta y Ésera, estableciendo dicha correlación para cada uno, aunque debido al escaso número de observatorios situados en el Ésera, hemos unido este sector con el del Cinqueta (Tabla 3).

En cada uno de los sectores hemos realizado una correlación lineal y otra logarítmica, obteniendo diversos coeficientes de correlación, como después analizaremos.

Una vez realizada las correlaciones precipitación-altitud en cada sector mencionado, hemos hallado la correlación regional utilizando todos los pluviómetros, tanto totalizadores como de lectura diaria, utilizados en el trabajo. Finalmente, usando las correlaciones que mayor ajuste han ofrecido en cada sector (lineal o logarítmica), hemos dibujado el mapa de isoyetas del Alto Cinca. 


\begin{tabular}{|c|c|c|c|c|c|c|c|c|c|c|c|c|c|}
\hline & \multicolumn{2}{|c|}{ Cuenca del Ara } & \multirow[b]{2}{*}{ Bre.Roland } & \multirow[b]{2}{*}{ Batanes } & \multicolumn{2}{|c|}{ Cuenca del Cinca } & \multirow[b]{2}{*}{ Urdiceto } & \multirow[b]{2}{*}{ Ig.Marbor } & \multirow[b]{2}{*}{ Pto Viejo } & \multicolumn{3}{|c|}{ Cuenca del Cinqueta } & \multirow{2}{*}{\begin{tabular}{|l|} 
C.Ésera \\
Bañ. Bena \\
\end{tabular}} \\
\hline & Otal & La Pazosa & & & Lg Lalarri & Escuain & & & & Pta. La Pea & Cruz de G. & Millares & \\
\hline $61-62$ & 2185 & 1922 & 1913 & 1327 & 1957 & & 1676 & 1823 & 1465 & 1443: & 18 & 1401 & \\
\hline $62-63$ & 2460 & 22256 & 2086 & 11972 & 2282 & & 1950 & 2293 & 1635 & 1676 & 1199 & 1970 & \\
\hline 63-64 & 2695 & 2481 & 2339 & 1784 & 2734 & & 2283 & 2617 & 181 & 1823 & 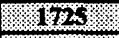 & 2352 & \\
\hline 64-65 & 1382 & 1221 & 1460 & 1156 & 2117 & & 1901 & 2206 & 1245 & 1470 & 1464 & 1480 & \\
\hline 65-66 & 3097 & 3518 & 2803 & 2087 & 2185 & & 1970 & 2225 & 1686 & 1695 & 1774 & 2264 & \\
\hline 66-67 & 2724 & 2078 & 1950 & 1166 & 2176 & & 1744 & 1823 & 1512 & 1970 & 1137 & 1774 & \\
\hline 67.68 & 2803 & 2362 & 2705 & 2166 & 2509 & & 2342 & 2558 & 1823 & 1921 & 1665 & 2244 & \\
\hline $68-69$ & 2499 & 2440 & 2264 & 1578 & 2323 & & 2136 & 2460 & 1793 & 1676 & 1480 & 1872 & \\
\hline $69-70$ & 2401 & 1842 & 1872 & 1235 & 2068 & & 1744 & 1725 & 1901 & 1578 & 1382 & 1431 & \\
\hline $70-71$ & 2813 & 2332 & 2166 & 1578 & 2097 & & 2185 & 2097 & 1784 & 1744 & 1627 & 1950 & \\
\hline \begin{tabular}{|l}
$71-72$ \\
\end{tabular} & 2215 & 2019 & 1931 & 1411 & 2215 & & 1735 & 1921 & 1656 & 1725 & 1480 & 1872 & \\
\hline \begin{tabular}{|l|}
$72-73$ \\
\end{tabular} & 2323 & 1686 & 1803 & 1186 & 1627 & & 1558 & 1659 & 1480 & 1548 & 1264 & 1480 & 1145 \\
\hline $73-74$ & 2352 & 2048 & 2097 & 1303 & 1284 & 1460 & 1735 & 1872 & 1382 & 1450 & 1284 & 1813 & \\
\hline $74-75$ & 1999 & 2509 & 1921 & 1215 & 2705 & 1284 & 1627 & 1852 & 1431 & 1578 & 1215 & 1372 & \\
\hline \begin{tabular}{|l|}
$75-76$ \\
\end{tabular} & 1490 & 1245 & 1392 & 855 & 1382 & 1137 & 1303 & 1431 & 1039 & 1088 & 963 & 1088 & \\
\hline $76-77$ & 2950 & 2607 & 2166 & 1578 & 2087 & 1813 & 1823 & 2411 & 1784 & 1764 & 1656 & 1921 & 21300 \\
\hline $77-78$ & 2479 & 2558 & 2117 & 1519 & 4086 & 1597 & 1725 & 2215 & 1548 & 1480 & 1186 & 1597 & 2157 \\
\hline $78-79$ & 2852 & 3538 & 4557 & 1480 & 1950 & 2087 & 2166 & 3126 & 1705 & 1872 & 1558 & 1578 & 2007 \\
\hline $79-80$ & 1882 & 1989 & 2185 & 1284 & 1588 & 1186 & 1705 & 1715 & 1441 & 1460 & 1362 & 1147 & 1232 \\
\hline $80-81$ & 1774 & 1627 & 1940 & 1313 & 2019 & 1205 & 1715 & 1970 & 1382 & 1480 & 1294 & 1137 & 1757 \\
\hline $81-82$ & 2264 & 2323 & 2362 & 1578 & 2332 & 1372 & 1725 & 2313 & 1676 & 1578 & 1676 & 1578 & 1157 \\
\hline $82-83$ & 2813 & 2362 & $2300 \%$ & 1901 & & 1490 & 1725 & 2421 & 1480 & 1529 & 1529 & 1676 & 1982 \\
\hline $83-84$ & 1970 & 1578 & 1172 & 990 & & 1284 & 1568 & 1294 & 1107 & 1225 & 1117 & 1107 & 1507 \\
\hline $84-85$ & 2479 & 2460 & 2008 & 1431 & & 1401 & 1617 & 2038 & 1480 & 1597 & 1000 & 1754 & 1957 \\
\hline $85-86$ & 1980 & 1989 & 168 & 1186 & & 1225 & 1715 & 1627 & 1137 & 1126 & 1137 & 981 & 1057 \\
\hline $86-87$ & 2313 & 1891 & 1774 & 1382 & & 1421 & 1529 & 2048 & 1411 & 1529 & 1205 & 1372 & 1707 \\
\hline $87-88$ & 3146 & 2568 & 2509 & 1725 & & 1901 & 2087 & 2852 & 2068 & 1578 & 1539 & 1862 & 2207 \\
\hline $88-89$ & 1480 & 1264 & 1245 & 855 & & 1186 & 1186 & 1235 & 1166 & 1000 & 972 & 1137 & 1257 \\
\hline $89-90$ & 2068 & 1627 & 1676 & 1284 & & 1362 & 1401 & 1509 & 1421 & 1205 & 1039 & 1147 & 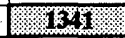 \\
\hline $90-91$ & 2215 & 1725 & 1382 & 1186 & & 1235 & 1352 & 1058 & 1235 & 1274 & 1205 & 1147 & 1207 \\
\hline Media & 2337 & 2136 & 2083 & 1394 & 2177 & 1425 & 1764 & 2015 & 1526 & 1536 & 1361 & 1583 & 1613 \\
\hline
\end{tabular}

Tabla 2. Precipitación anual en los totalizadores (mm). Annual precipitation in the totalizators $(\mathrm{mm})$. 


\begin{tabular}{|l|c|c|c|}
\hline \multicolumn{2}{|l|}{ Cuenca del Ara } & & \\
\hline & $\mathbf{N}^{\circ}$ & Altitud & Prec. \\
\hline Otal & 1 & 1862 & 2337 \\
\hline La Pazosa & 2 & 2230 & 2136 \\
\hline B.Rolando & 3 & 2310 & 2083 \\
\hline Los Batanes & 4 & 2000 & 1407 \\
\hline Toria & 5 & 1053 & 1326 \\
\hline Broto & 6 & 1005 & 1189 \\
\hline Fragen & 7 & 1113 & 1216 \\
\hline Asín de Bro & 8 & 1103 & 1110 \\
\hline \hline Cuenca del Cinca & & \\
\hline & & Altitud & Prec. \\
\hline La Larri & 9 & 2500 & 2177 \\
\hline Escuaín & 10 & 1340 & 1425 \\
\hline Urdiceto & 11 & 2360 & 1764 \\
\hline Lag. Marbor. & 12 & 2590 & 2015 \\
\hline Puerto Viejo & 13 & 2030 & 1526 \\
\hline Pineta & 14 & 1150 & 1400 \\
\hline Buerba & 15 & 1143 & 1227 \\
\hline Barrosa Cen & 16 & 1200 & 1347 \\
\hline Parzán & 17 & 1050 & 1377 \\
\hline Fanlo & 18 & 1320 & 1613 \\
\hline \hline Cuenca del Cinqueta & & \\
\hline & & Altitud & Prec. \\
\hline Pta.La Pez & 19 & 1800 & 1536 \\
\hline Cruz Guard & 20 & 2120 & 1361 \\
\hline Millares & 21 & 2390 & 1583 \\
\hline S.J. Plan & 22 & 1124 & 1237 \\
\hline Gistain & 23 & 1422 & 1366 \\
\hline Plandesc & 24 & 1100 & 1222 \\
\hline Sin & 25 & 1218 & 1229 \\
\hline \hline Cuenca del Esera & & \\
\hline Ban. Benas & 26 & 1720 & 1644 \\
\hline Benas Viv & 27 & 1130 & 1213 \\
\hline Eriste & 28 & 1100 & 1125 \\
\hline
\end{tabular}

Tabla 3. Altitud $(\mathrm{m})$ y precipitación media anual $(\mathrm{mm})$ de pluviómetros y totalizadores Raingages and totalizators height $(\mathrm{m})$ and annual average precipitation $(\mathrm{mm})$. 


\section{Resultados}

\section{La precipitación media anual}

El Alto Cinca es una zona que recibe abundantes precipitaciones, las cuales aumentan notablemente con la altura, aunque con diferencias según los sectores, como desarrollaremos más adelante.

En los valles, donde se sitúan los principales núcleos de población y en ellos la mayoría de los pluviómetros instalados por el I. N. M., la precipitación supera los $1200 \mathrm{~mm}$ :

Fragen, en el Ara, a $1113 \mathrm{~m}$ recoge $1209 \mathrm{~mm}$ de precipitación media. Buerba, en el Cinca, a 1143 m, 1226 mm, San Juan de Plan, en el Cinqueta, a $1124 \mathrm{~m}, 1234 \mathrm{~mm}$, y Benasque «Vivero», en el Ésera, a 1130 m, 1219 mm.

Estas cantidades se incrementan notablemente con la altitud:

El totalizador de Los Batanes, en el Ara, recoge $1394 \mathrm{~mm}$ de media a 2000 $\mathrm{m}$. El del Puerto Viejo, en el Cinca, $1526 \mathrm{~mm}$ a $2030 \mathrm{~m}$. El del puerto de La Pez, en el Cinqueta $1536 \mathrm{~mm}$ a $1800 \mathrm{~m}$, y el de Los Baños de Benasque, en el Ésera $1613 \mathrm{~mm}$ a $1720 \mathrm{~m}$.

En cotas superiores las cantidades son las siguientes:

El totalizador de La Pazosa, en el Ara, a $2230 \mathrm{~m}$ recoge $2136 \mathrm{~mm}$. El de La Larri, en el Cinca, a $2500 \mathrm{~m}$ recibe $2177 \mathrm{~mm}$. El de Los Millares, en el Cinqueta, a $2390 \mathrm{~m}$ registra $1583 \mathrm{~mm}$.

\section{La Precipitación y la altitud}

En el Alto Cinca la precipitación aumenta considerablemente al ganar altura. En conjunto, si observamos la correlación precipitación-altitud realizada entre todos los observatorios (tanto pluviómetros como totalizadores) utilizados en el trabajo (Gráfico 1) obtenemos un coeficiente de 0.7831 en la correlación lineal y de 0.7830 en la logarítmica, que podemos considerar muy significativo del aumento general de las lluvias a medida que ascendemos.

Según la correlación lineal, que muestra un coeficiente ligerísimamente superior a la logarítmica:

- A $1500 \mathrm{~m}$ de altitud se registrarían $1457 \mathrm{~mm}$ anuales.

- A $2000 \mathrm{~m}$ de altitud se registrarían $1709 \mathrm{~mm}$ anuales.

- A $2500 \mathrm{~m}$ de altitud se registrarían $1962 \mathrm{~mm}$ anuales.

Según la correlación logarítmica, la precipitación media anual a idéntica altitud sería:

- A $1500 \mathrm{~m}$ de altitud se registrarían $1498 \mathrm{~mm}$ anuales.

- A $2000 \mathrm{~m}$ de altitud se registrarían $1736 \mathrm{~mm}$ anuales. 
LA PRECIPITACIÓN MEDIA ANUAL EN EL SECTOR ALTO DE LA CUENCA DEL CINCA
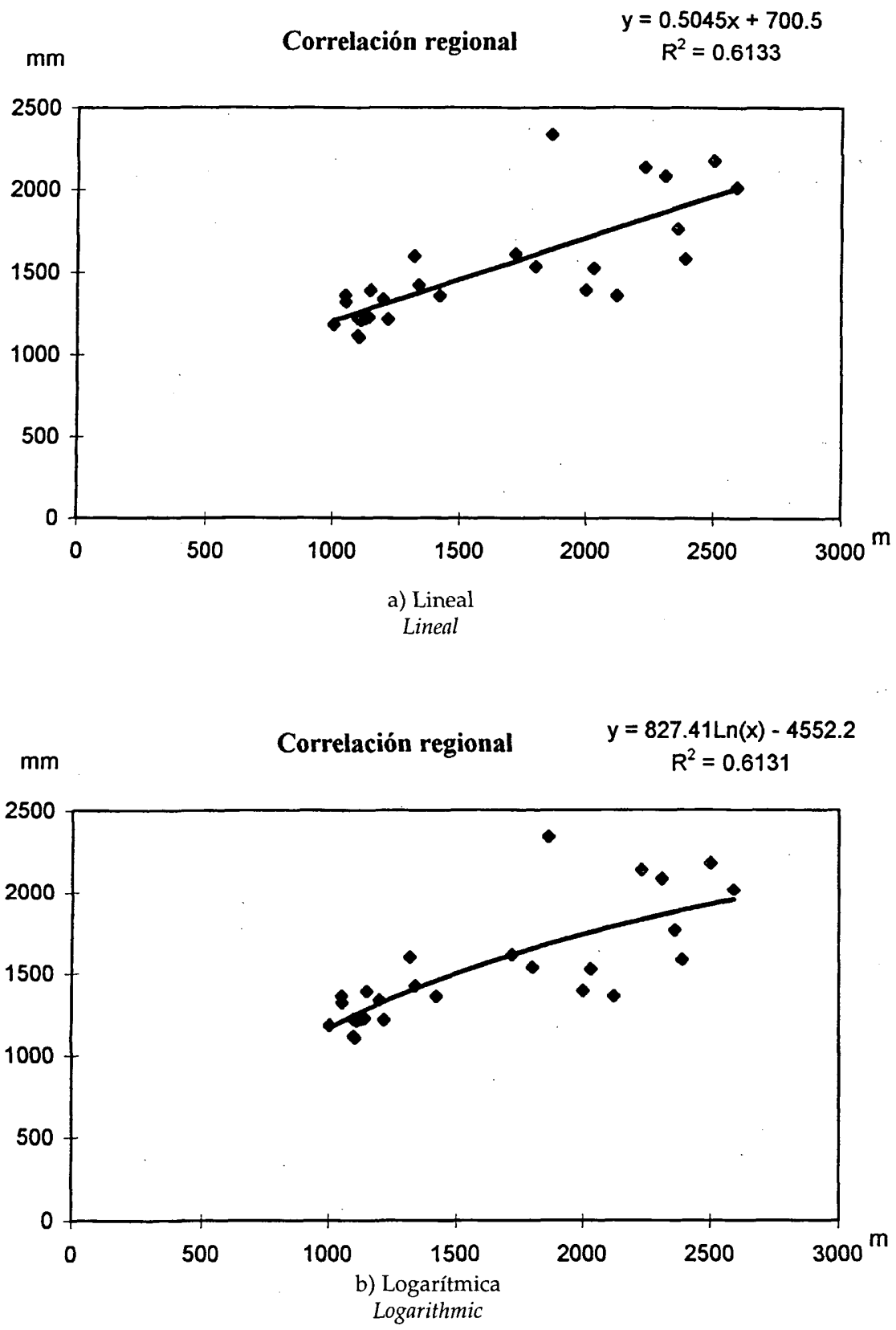

Gráfico 1. Correlación precipitación-altitud en la zona de estudio.

Precipitation-height correlation in the studied area. 
- A $2500 \mathrm{~m}$ de altitud se registrarían $1921 \mathrm{~mm}$ anuales.

Sin embargo, consideramos interesante analizar por sectores las variaciones de la precipitación con la altitud, pues muestra comportamientos diferenciados:

- En la cuenca del Ara el coeficiente de correlación logarítmica es de 0.820 , que podemos considerar muy bueno (Gráfico 2). Es algo superior al hallado utilizando la correlación lineal (0.816), por lo cual es el que hemos utilizado para trazar las isolíneas en este sector (Mapa 2). Según esta correlación:

- A $1500 \mathrm{~m}$ de altitud se registrarían $1600 \mathrm{~mm}$ anuales.

- A $2000 \mathrm{~m}$ de altitud se registrarían $1922 \mathrm{~mm}$ anuales.

- A $2500 \mathrm{~m}$ de altitud se registrarían $2171 \mathrm{~mm}$ anuales.

El coeficiente de correlación obtenido es muy alto, pero hay dos observatorios que se separan notablemente de la curva de regresión, lo que merece algún comentario:

- El totalizador de Otal, que a 1862 m recibe una precipitación media de $2337 \mathrm{~mm}$ presenta una clara desviación positiva respecto a la curva de regresión.

- El totalizador de Los Batanes, que a $2000 \mathrm{~m}$ recoge $1407 \mathrm{~mm}$, presentando una desviación negativa respecto a la curva de regresión.

No hemos encontrado indicios suficientes para considerar estos observatorios poco fiables, por lo que los hemos utilizado como el resto, pero sus desviaciones respecto a la curva de regresión merecen una explicación:

El totalizador de Otal se encuentra en el valle del mismo nombre (afluente del Ara por su margen derecha) en la vertiente $\mathrm{N}$ de sierra Tendeñera, murallón topográfico de considerable altitud y marcada disposición O-E que puede ejercer una influencia sobre las masas de aire húmedas que vienen del $\mathrm{NO}$, reforzando la inestabilidad y favoreciendo la precipitación, lo que se traduce en un aumento de la cantidad de lluvia de ámbito local.

El totalizador de Los Batanes se encuentra a $2000 \mathrm{~m}$ de altura pero en el fondo del valle de Bujaruelo y próximo a su cabecera, muy cerrada por macizos montañosos (Vignemale al N y NE, etc.)

- En la cuenca del Cinca el coeficiente de correlación lineal asciende a 0.901 (Gráfico 3), mientras el de correlación logarítmica es de 0.886. Por lo tanto, el primero es el que hemos empleado para calcular la precipitación a diferentes cotas y trazar las isoyetas (Mapa 3). Según estos resultados:

- A $1500 \mathrm{~m}$ de altitud se registrarían $1506 \mathrm{~mm}$ anuales.

- A $2000 \mathrm{~m}$ de altitud se registrarían $1730 \mathrm{~mm}$ anuales.

- A $2500 \mathrm{~m}$ de altitud se registrarían $1955 \mathrm{~mm}$ anuales. 
LA PRECIPITACIÓN MEDIA ANUAL EN EL SECTOR ALTO DE LA CUENCA DEL CINCA

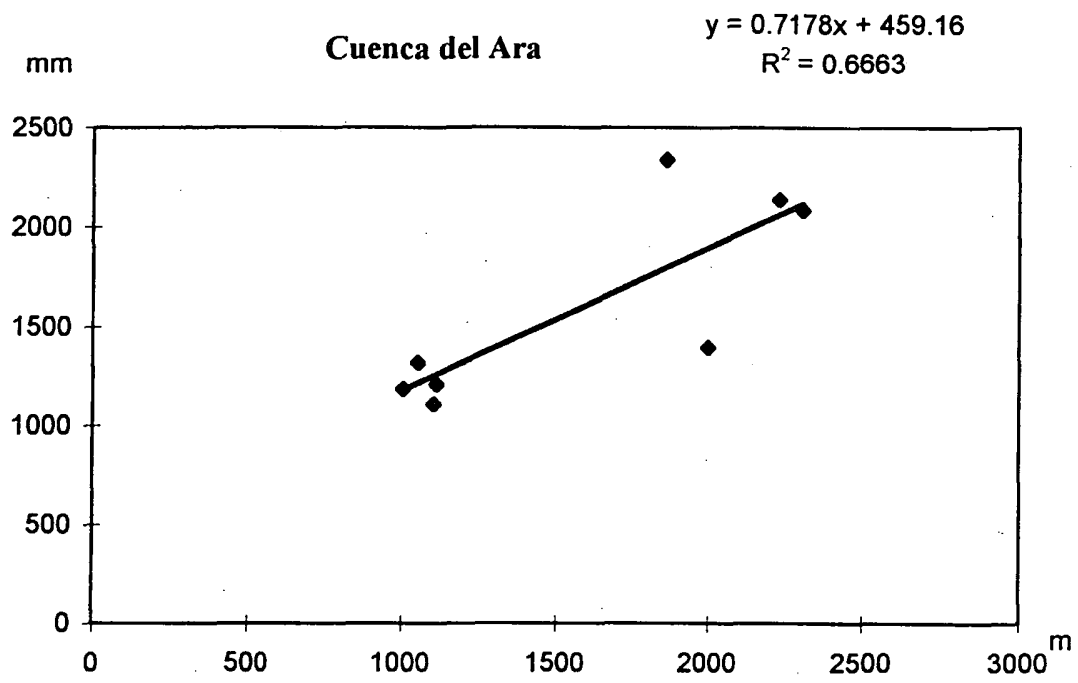

a) Lineal

Lineal

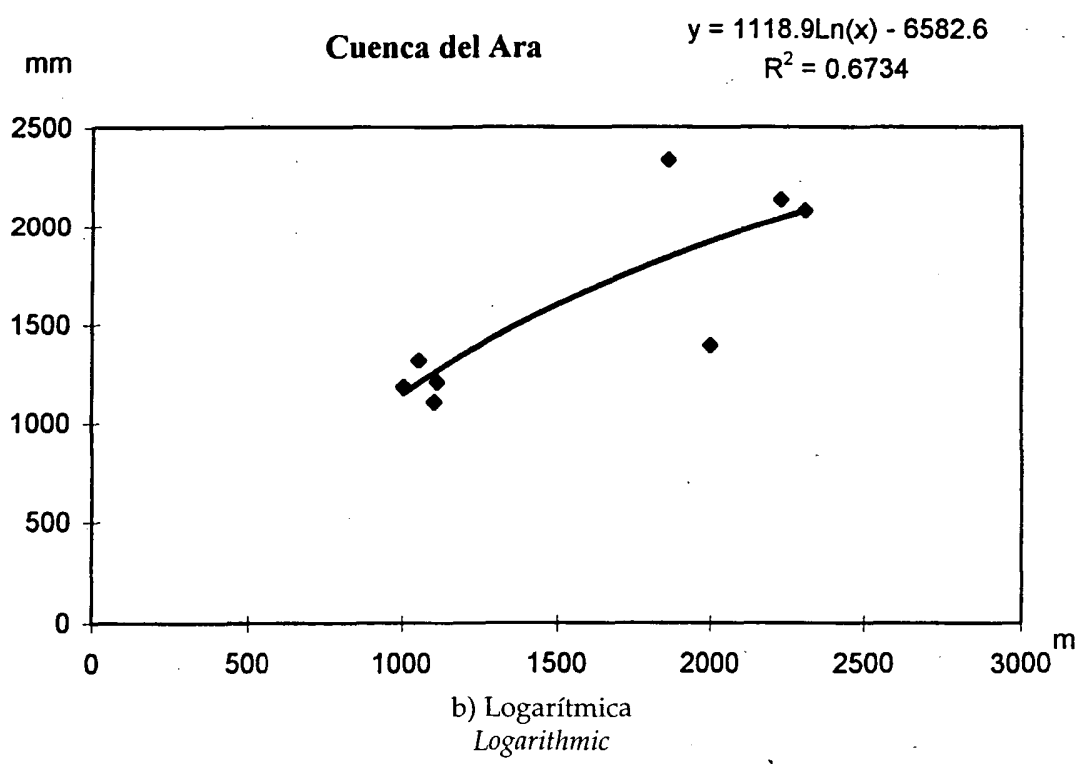

Gráfico 2. Correlación precipitación-altitud en la cuenca del Ara.

Precipitation-height correlation in Ara basin. 
PIRINEOS $149-150$

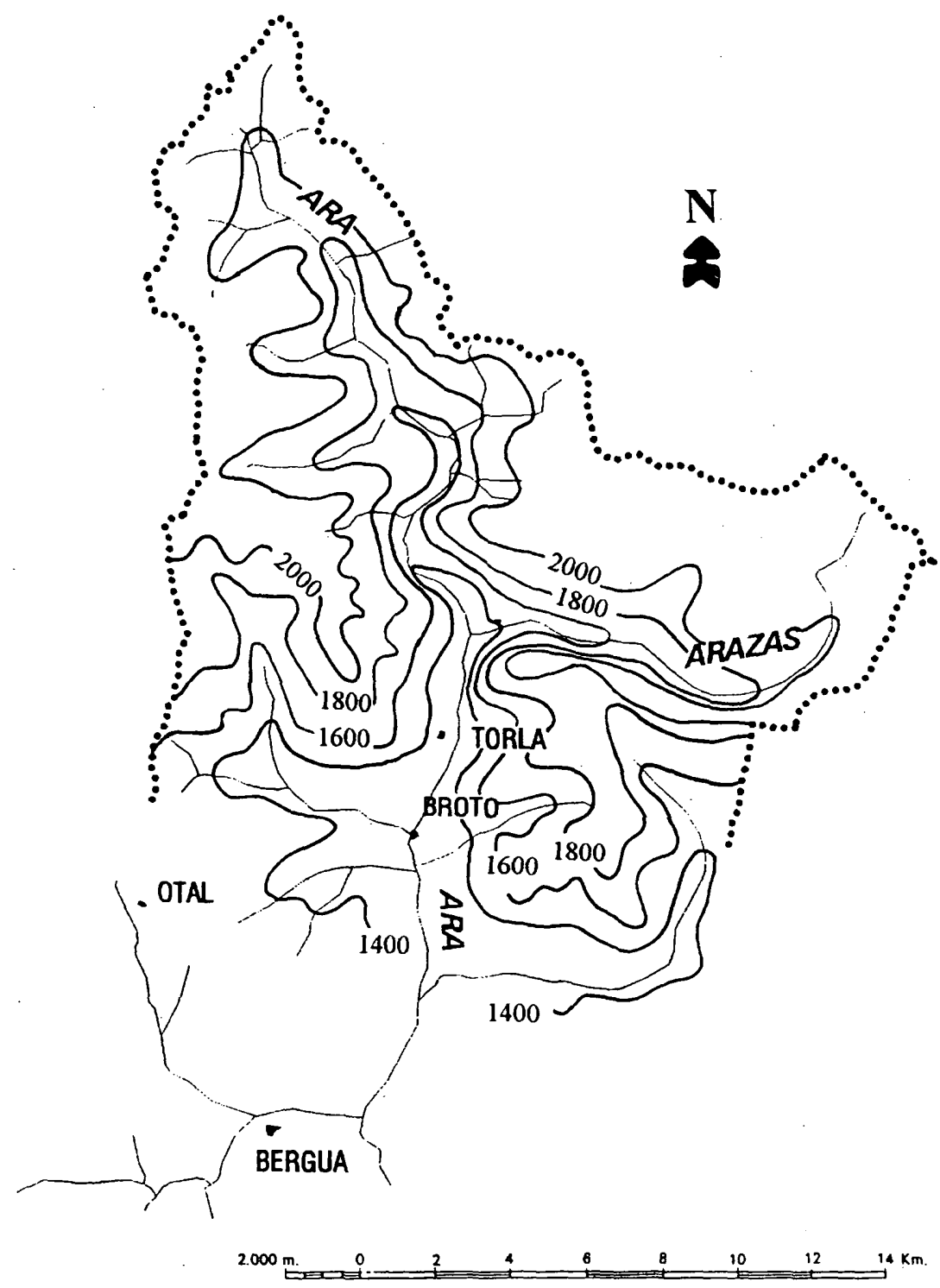

Mapa 2. Precipitación media anual (mm) en la cuenca alta del Ara. Upper Ara basin annual average precipitation $(\mathrm{mm})$. 
LA PRECIPITACIÓN MEDIA ANUAL EN EL SECTOR ALTO DE LA CUENCA DEL CINCA
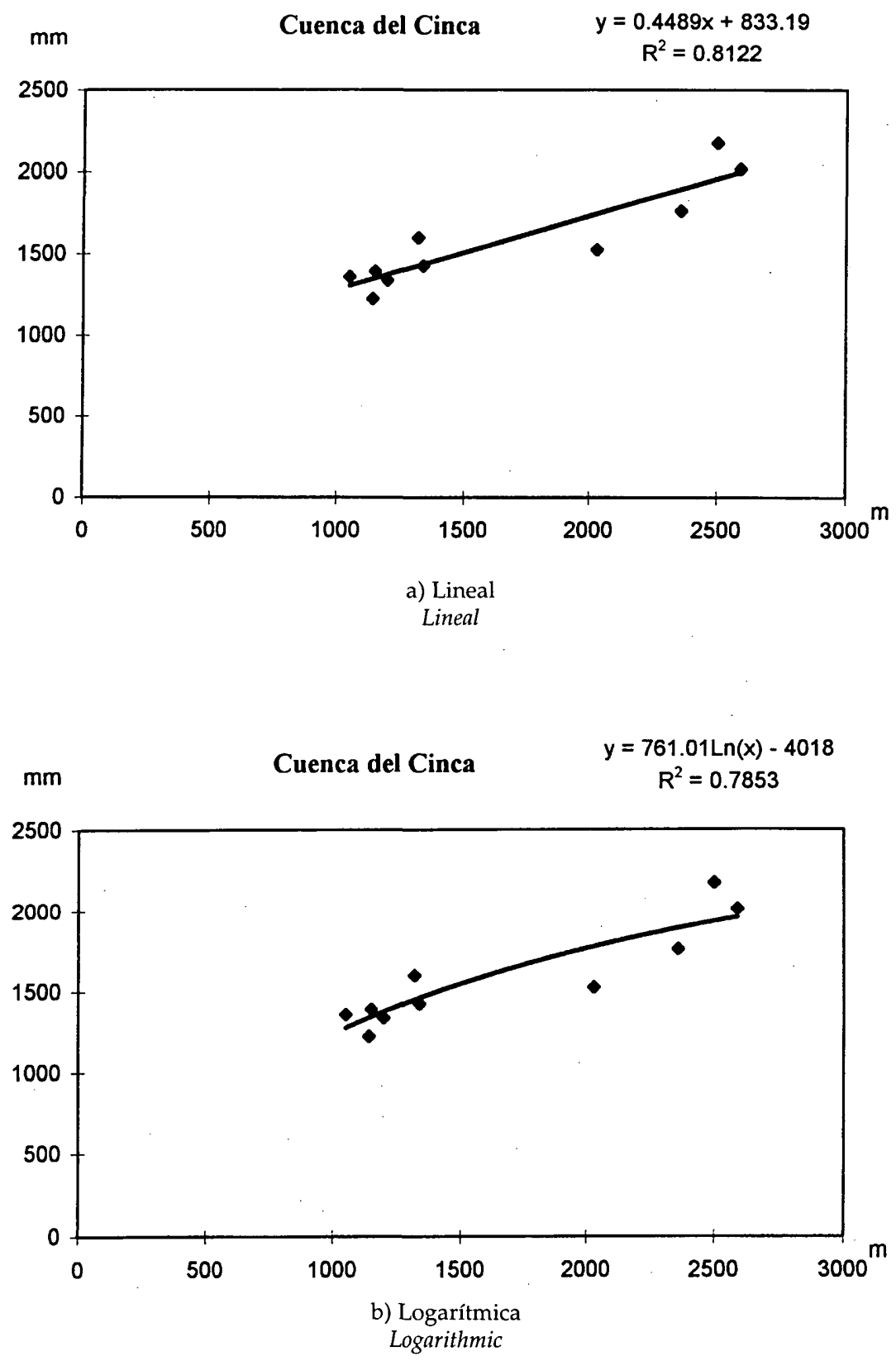

Gráfico 3. Correlación precipitación-altitud en la cuenca del Cinca.

Precipitation-height correlation in Cinca basin. 


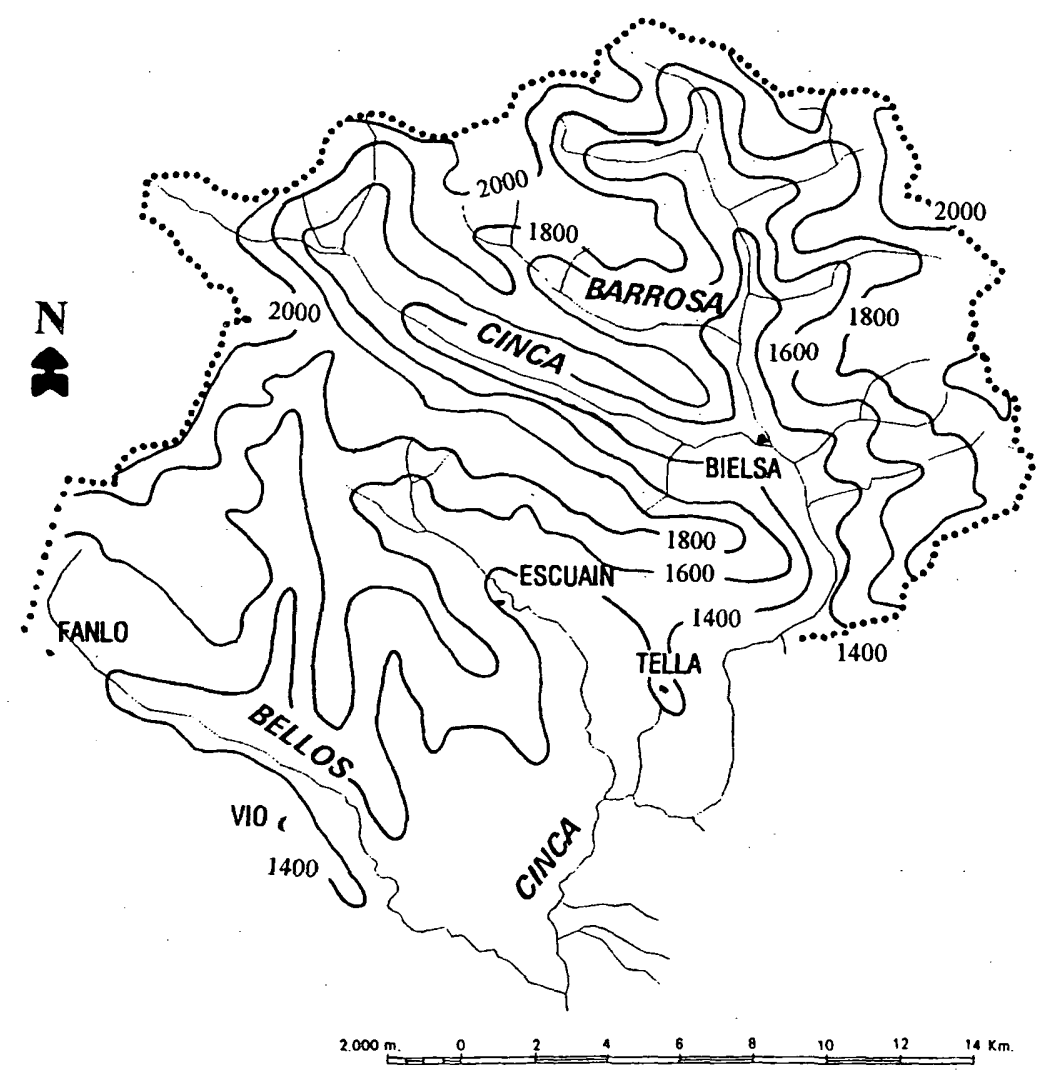

Mapa 3. Precipitación media anual ( $\mathrm{mm}$ ) en la cuenca alta del Cinca. Upper Cinca basin annual average precipitation $(\mathrm{mm})$.

En esta cuenca ningún pluviómetro se separa de forma apreciable de la línea de ajuste, sólo podemos mencionar una cierta separación negativa respecto a ella en el totalizador de Puerto Viejo, que explicamos por la localización de éste en un valle de orientación $\mathrm{SE}$, muy cerrada por el $\mathrm{O}$ y NO por macizos y cordales montañosos (entre los que destaca el de La Munia, con $3133 \mathrm{~m}$ ), lo que sin duda se traduce en una cierta sombra de lluvia.

El totalizador de La Larri presenta una ligera separación positiva respecto a la recta de ajuste, pero a nuestro juicio se debe a que su serie termina en la campaña 81-82, y no incluye por lo tanto la mitad de la década de los años ochenta, que en general fue bastante seca.

- En las cuencas del Cinqueta y Ésera el coeficiente de correlación logarítmica es de 0.841 (Gráfico 4), superior al de correlación lineal (0.809), por lo 
LA PRECIPITACIÓN MEDIA ANUAL EN EL SECTOR ALTO DE LA CÚENCA DEL CINCA
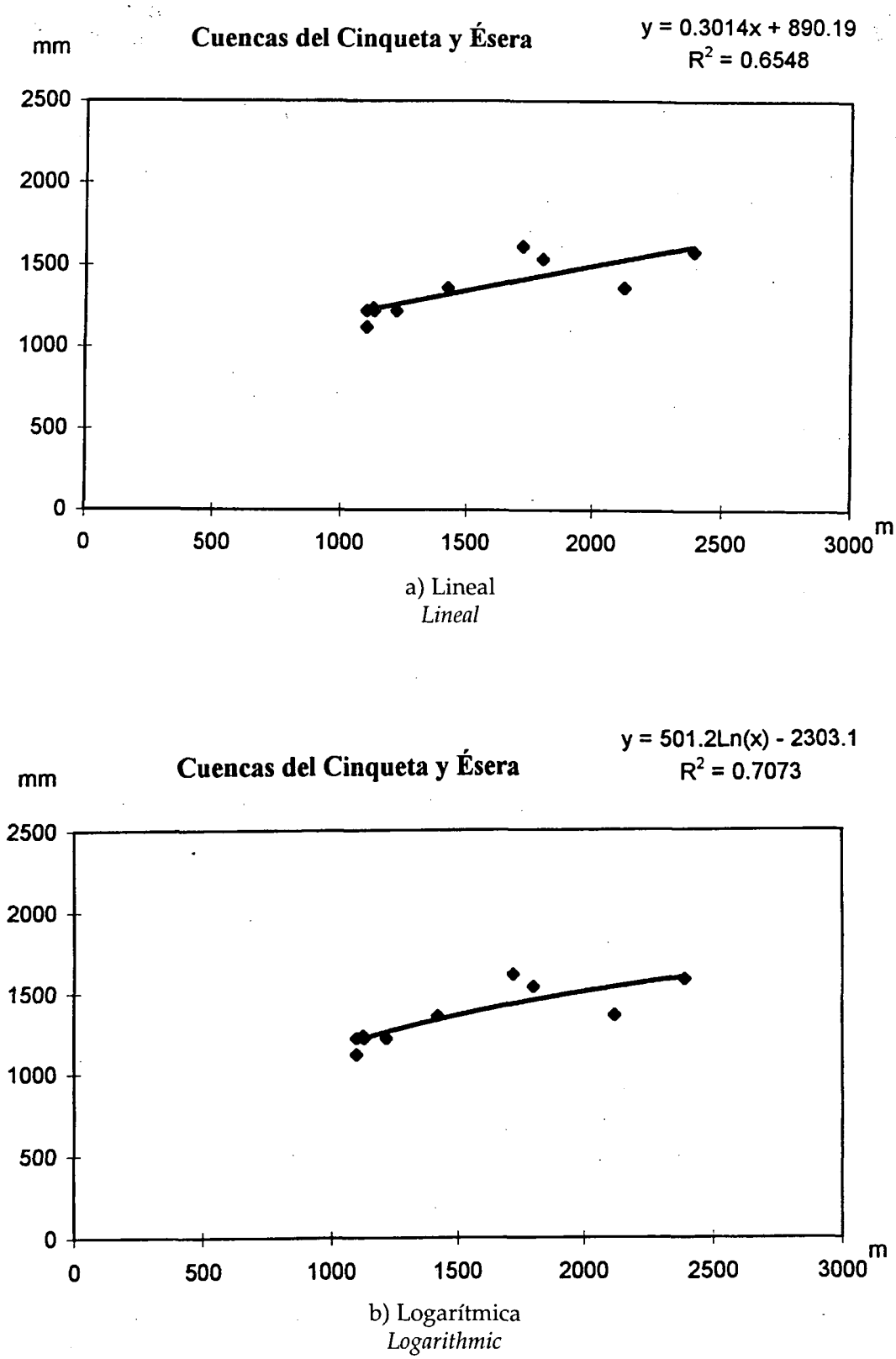

Gráfico 4. Correlación precipitación-altitud en las cuencas del Ésera y Cinqueta. Precipitation-height correlation in Ésera and Cinqueta basins. 
cual es el que hemos utilizado para trazar las isoyetas (Mapa 4). Según la ecuación de ajuste, la precipitación media anual sería:

- A $1500 \mathrm{~m}$ se registrarían $1362 \mathrm{~mm}$.

- A $2000 \mathrm{~m}$ se registrarían $1506 \mathrm{~mm}$.

- A $2500 \mathrm{~m}$ se registrarían $1618 \mathrm{~mm}$.

De los observatorios considerados, dos se separan ligeramente de la línea de regresión, aunque en ningún caso de forma sustancial: El totalizador de Baños de Benasque muestra una cierta desviación positiva, probablemente debido a su localización por encima del fondo del valle, en una ladera orientada hacia el NO y por lo tanto bien expuesta a los vientos húmedos dominantes, aunque cuando llegan aquí ya han perdido buena parte de su humedad. El totalizador de la Cruz de Guardia presenta una cierta desviación negativa, que a nuestro juicio se debe a su localización en un collado muy abierto en la divisoria entre las cuencas del Cinqueta y Cinca, en el que muy probablemente se produzcan fuertes vientos y turbulencias que pueden provocar una ligera disminución local de la precipitación.

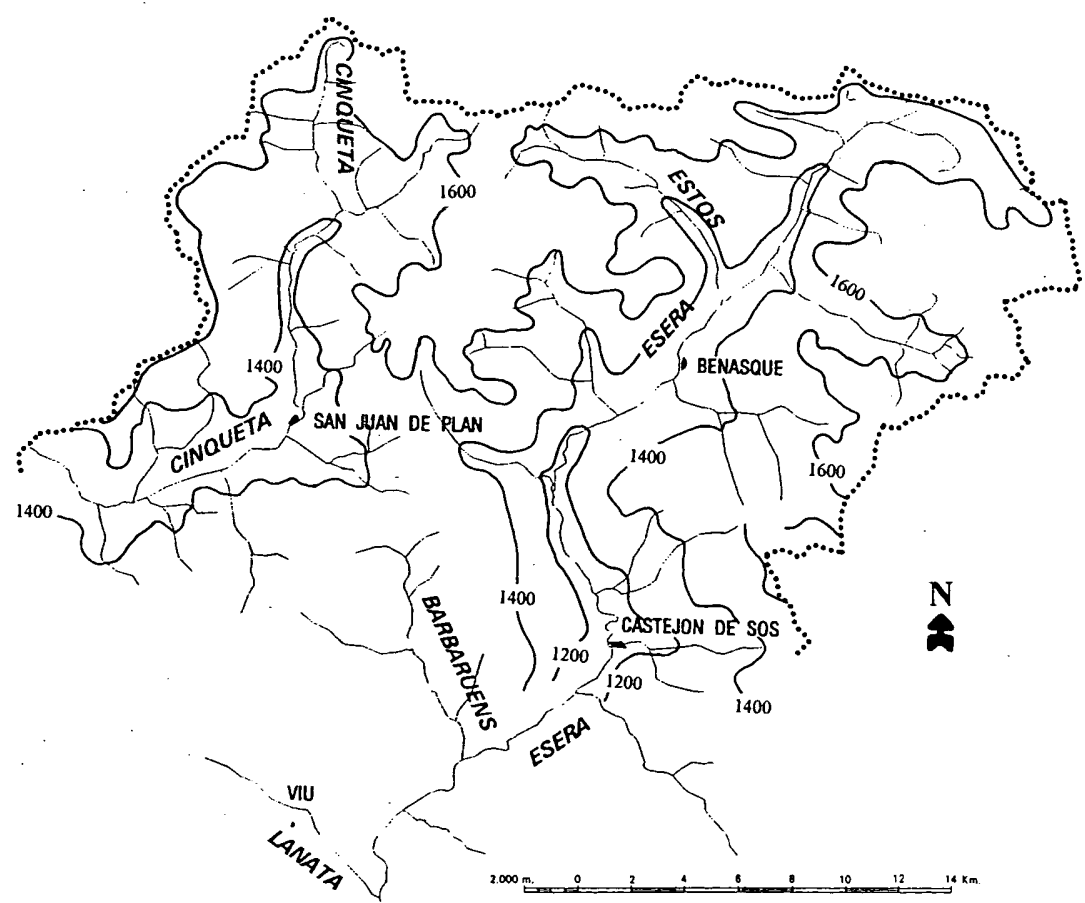

Mapa 4. Precipitación media anual (mm) en las cuencas altas del Cinqueta y del Ésera. Upper Cinqueta and Ésera basins annual average precipitation $(\mathrm{mm})$. 
La zona considerada presenta, en su conjunto, un gradiente de $51 \mathrm{~mm} / 100$ $\mathrm{m}$, aunque con diferencias entre unos valles y otros, pues resulta máximo al $\mathrm{O}$ (Ara) y mínimo al E (Cinqueta y Ésera). Si atendemos a los resultados de las correlaciones lineales, los gradientes por cuencas son:

- Ara: $71.8 \mathrm{~mm} / 100 \mathrm{~m}$.

- Cinca: $44.9 \mathrm{~mm} / 100 \mathrm{~m}$.

- Cinqueta y Ésera: $30.1 \mathrm{~mm} / 100 \mathrm{~m}$.

Estas cifras en algunos casos se diferencian de las obtenidas por CUADRAT (1981), quien fija el gradiente en el Cinca en $74 \mathrm{~mm}$ y en el Ésera en $61 \mathrm{~mm}$, aunque considera los tramos situados aguas arriba de Aínsa y de Campo respectivamente, por lo que incluye un sector mayor de cada cuenca que el considerado en el presente estudio. Por el contrario el gradiente obtenido en el Ara por el citado autor $(72 \mathrm{~mm})$, abarcando íntegra su cuenca desde su desembocadura en Aínsa, es muy similar al nuestro.

Según estos resultados la precipitación media anual a igual altitud va disminuyendo a medida que nos desplazamos de $\mathrm{O}$ a $\mathrm{E}$, siendo por lo tanto máxima en la cuenca del Ara y mínima en la del Ésera. Este fenómeno se justifica según la mayor o menor facilidad que presentan estas cuencas a la llegada de los vientos húmedos, que principalmente proceden del Atlántico y por lo tanto llegan desde el NO.

Cuando estas masas de aire oceánico llegan a nuestra zona, ya han atravesado una buena parte de la cordillera pirenaica, en la que han perdido una parte de su humedad, pérdida en parte compensada por la mayor altitud de la cordillera hacia el E, que refuerza los procesos de inestabilización y por lo tanto facilita que alcancen su punto de saturación.

Sin embargo, la zona de estudio limita al O precisamente con la divisoria entre las cuencas del Ara y Gállego, que constituye una importante barrera pluviométrica (GARCÍA RUIZ et al., 1985). La cuenca alta del Cinca y sus dos principales afluentes Ara y Ésera, se localiza en la zona central y oriental del Pirineo Aragonés, a la que corresponden condiciones de menor pluviometría que a la occidental (GARCÍA RUIZ et al., l. c.). Esta característica se va haciendo más acentuada a medida que avanzamos hacia el $\mathrm{E}$, como ya hemos expuesto, aunque siempre dentro de cantidades notablemente elevadas.

La disposición general N-S de las cabeceras del Ara, Cinca, Cinqueta y Ésera supone la existencia de interfluvios de la misma dirección, que actúan como barreras de lluvia, lo que significa progresivos procesos de desecación de las masas de aire húmedas dominantes en su desplazamiento NO-SE; ello se traduce en una pluviometría progresivamente menor en sentido O-E y menores gradientes de precipitación con la altitud. 


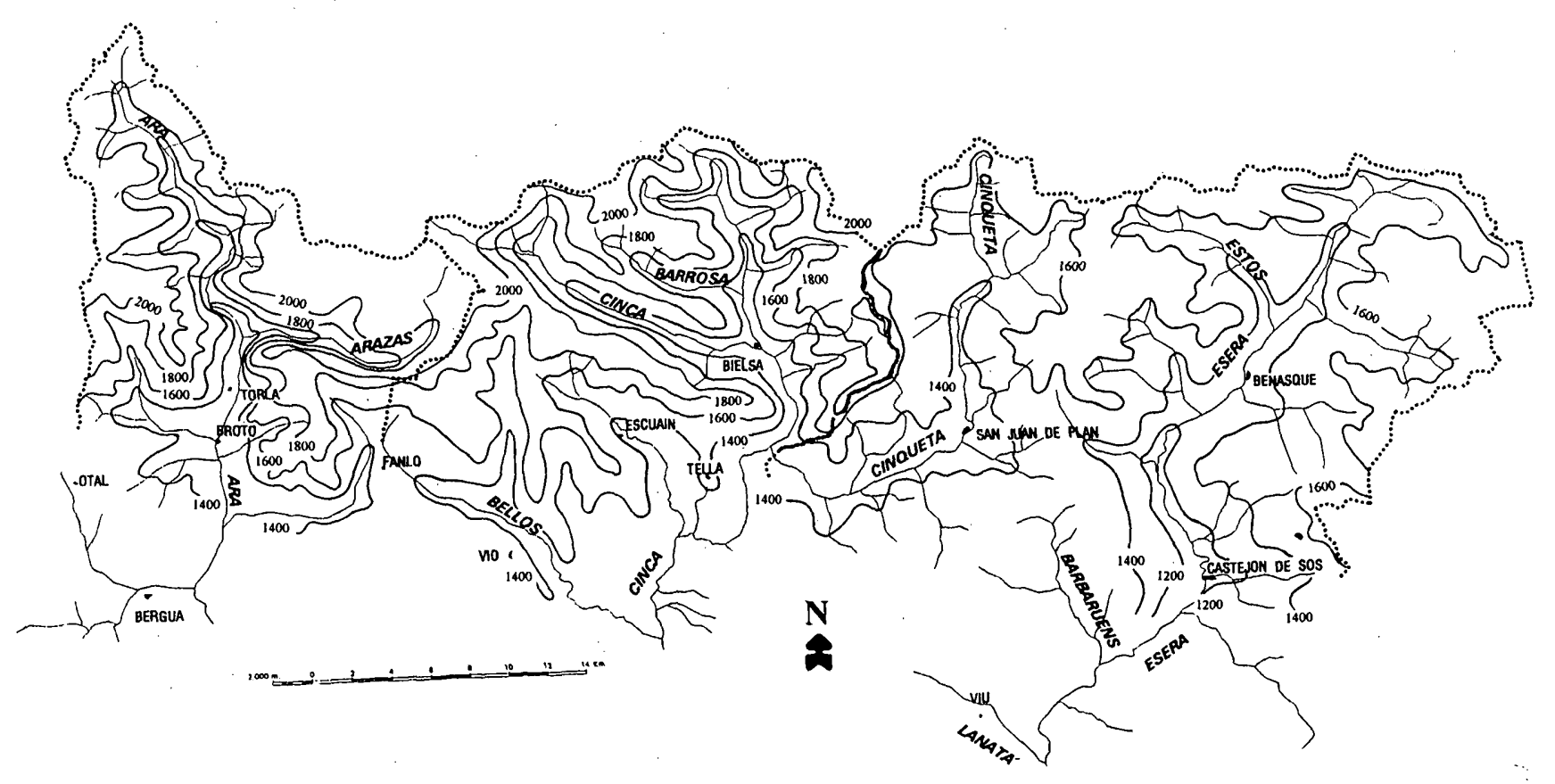

Mapa 5: Precipitación media anual ( $\mathrm{mm}$ ) en la zona de estudio. Studied area annual average precipitation $(\mathrm{mm})$. 


\section{Conclusiones}

Los datos climáticos en las zonas de alta montaña son escasos, lo que supone un serio condicionamiento para el detallado conocimiento de las condiciones climáticas de nuestras cordilleras, especialmente en sus sectores más elevados.

- Los totalizadores colocados por las compañías de electricidad en cotas elevadas son muy importantes para conocer las condiciones pluviométricas de estas montañas, pues complementan los datos obtenidos por los pluviómetros del I. N. M. localizados en los pueblos, y por lo tanto en cotas más bajas.

- En el Alto Cinca las precipitaciones son bastante abundantes y aumentan notablemente con la altitud. No obstante, este aumento presenta gradientes muy distintos para las tres subcuencas en que hemos dividido la cabecera:

- En el Ara: $71.8 \mathrm{~mm} / 100 \mathrm{~m}$.

- En el Cinca: $44.9 \mathrm{~mm} / 100 \mathrm{~m}$.

- En el Cinqueta y Ésera: $30.1 \mathrm{~mm} / 100 \mathrm{~m}$.

El gradiente altitudinal va disminuyendo, por tanto, a medida que nos desplazamos del $\mathrm{O}$ al E; al igual que la precipitación media, por lo cual a la misma altura se registran cantidades menores en sentido O-E. Así a $2000 \mathrm{~m}$ de altitud la precipitación media anual registrada sería:

- En la cuenca del Ara: $1922 \mathrm{~mm}$.

- En la cuenca del Cinca: $1730 \mathrm{~mm}$.

- En las cuencas del Cinqueta y Ésera: $1506 \mathrm{~mm}$.

Este hecho, coincidente con el comportamiento pluviométrico general del sector aragonés de la Cordillera, se ve reforzado por la disposición N-S de los valles, de modo que los interfluvios actúan como barreras orográficas $\mathrm{y}$, por lo tanto, facilitan los procesos de desecación de las masas de aire en su desplazamiento O-E.

- De los resultados obtenidos se deduce que hasta los 2000 - $2500 \mathrm{~m}$ la precipitación se incrementa con la altitud, por lo cual el óptimo pluviométrico ha de quedar por encima de este nivel. No obstante, en la cuenca del Ara este óptimo podría quedar situado hacia $2000 \mathrm{~m}$ o algo menos, pues los totalizadores localizados a mayor altitud muestran una precipitación media inferior a la del de Otal (2337 $\mathrm{mm}$ a $1862 \mathrm{~m})$. La cuenca del Ara es la más occidental y presenta mayor facilidad para la condensación de la humedad atlántica, por lo que no debe extrañar este hecho. 
Agradecimientos. A Eléctricas Reunidas de Zaragoza (E. R. Z.) y al Centro Meteorológico Territorial de Aragón, La Rioja y Navarra (Instituto Nacional de Meteorología) por las facilidades para la obtención y utilización de los datos.

\section{Referencias}

BORDERÍAS, M. P. (1975): Valle del Ésera. Estudio climático. Tesis de licenciatura inédita. Departamento de Geografía y Ordenación del Territorio, Universidad de Zaragoza.

CREUS NOVAU, J. (1983): El clima del Alto Aragón Occidental. Monografías del Instituto de Estudios Pirenaicos, n. ${ }^{\circ}$ 109. Jaca.

CREUS NOVAU, J. (1987): Algunas características climáticas de la alta montaña en los Pirineos Centrales. Actas del X Congreso Nacional de Geografía:137-146. Zaragoza.

CUADRAT PRATS, J. M. (1981): El Clima del Pirineo Central. Ensayo de aplicación al turismo de montaña. Tesis doctoral inédita. Departamento de Geografía y Ordenación del Territorio, Universidad de Zaragoza.

GARCİA RUIZ, J. M.; PUIGDEFÁBREGAS, J. \& CREUS NOVAU, J. (1985): Los recursos hídricos superficiales del Alto Aragón. Colección de Estudios Altoaragoneses, $\mathrm{n}^{\circ}{ }^{2}$. Instituto de Estudios Altoaragoneses. Huesca.

MARÍN JAIME, J. M. (1988): Estudio hidrológico de la cuenca alta y media del río Gállego. Tesis doctoral inédita. Departamento de Geografía y Ordenación del Territorio, Universidad de Zaragoza.

PLANA CASTELLVÍ, J. A. (1975): Balance hídrico de la Cuenca del Noguera Ribagorzana. Tesis doctoral inédita. Departamento de Geografía y Ordenación del Territorio, Universidad de Zaragoza.

PUIGDEFÁBREGAS, J. \& CREUS NOVAU, J. (1976): Pautas espaciales de variación climática en el Alto Aragón. Pub. Centro pirenaico de Biología experimental, 1 (7): 23-34.

VALLE MELENDO, J. del (1996): El Clima del Prepirineo central y occidental aragonés y sus somontanos. Serie Investigación, Consejo de Protección de la Naturaleza de Aragón. Zaragoza. 